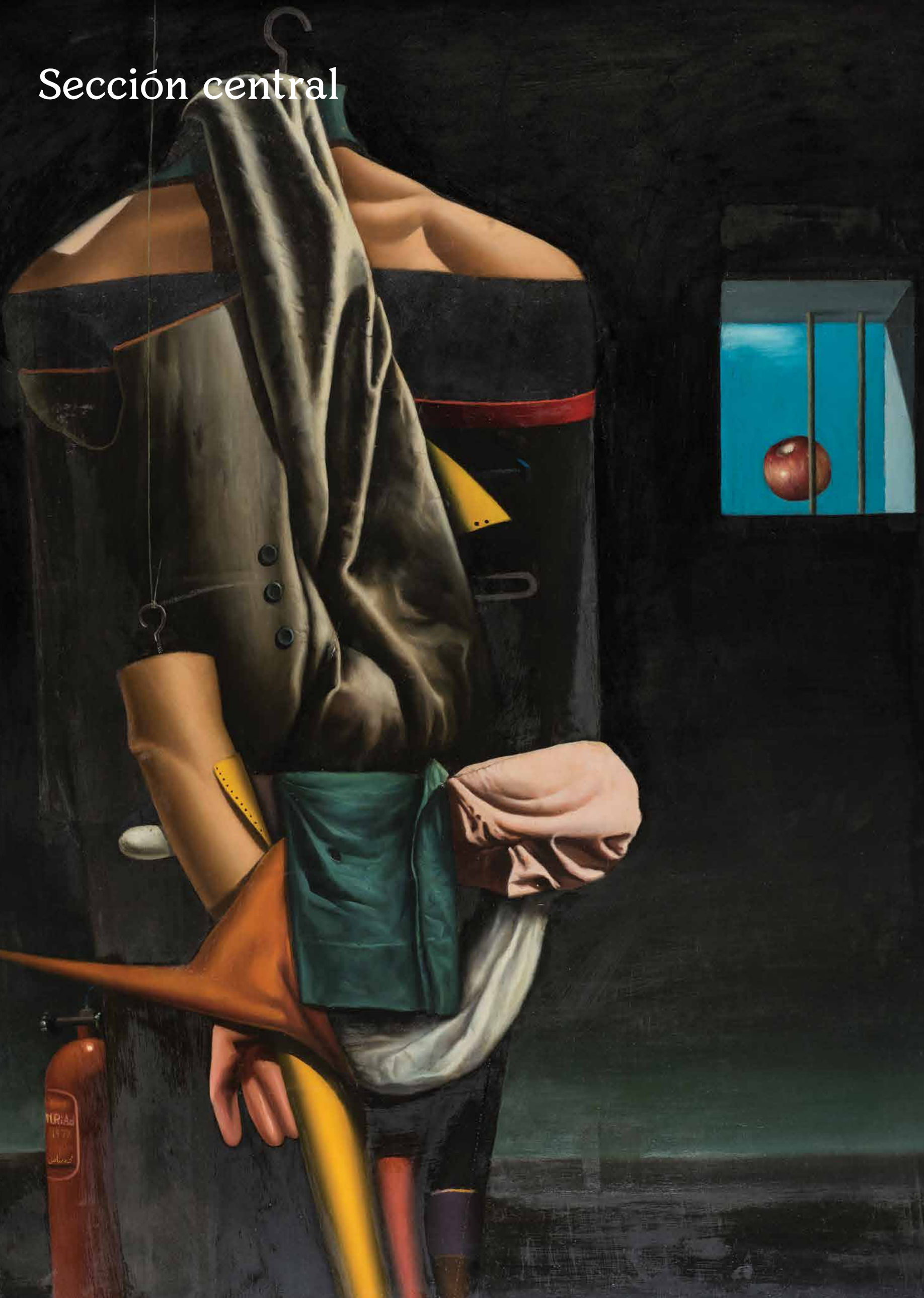




\section{Re-escribiendo la historia del modernismo en África*}

\section{Artículo de reflexión}

Recibido: 28 de abril de 2017

Aprobado: 12 de mayo de 2017

PhD. Lucrezia Cippitelli

cippitel@gmail.com

Accademia Belle Arti di Firenze

Universidad de Addis Abeba, Mòsso

* Traducción del inglés: Pedro Pablo Gómez

Cómo citar este artículo: Cippitelli, Lucrezia (2017). Re-escribiendo la Historia del Modernismo en África, Estudios Artísticos: revista de investigación creadora 3 (3) pp. 41-62. DOI: https://doiorg/ 10.1448/ear.v3i3.12527
Mohamed Riyad Saeed, Adams Apple, Oil on board, 122.5 x $149 \mathrm{~cm}$ Courtesy of Museum of Modern Egyptian Art in Cairo.

\section{Resumen}

En este artículo la autora se propone hacer visible la clara intención de una generación de productores culturales africanos empeñados en modelar la historia moderna de sus países y de reescribir la Historia del Modernismo artístico en África, desde una perspectiva no eurocéntrica; intención que se caracteriza por la apropiación de la heterogénea experiencia de los procesos de descolonización. Para tal fin, se realiza el análisis de dos importantes proyectos expositivos y académicos: Khartoum School: The Making of Modern Art Movement in Sudan (desde 1945 hasta el presente) co-curada por Hoor Al-Qasimi y Salah M. Hassan y When Arts Become Liberty: The Egyptian Surrealists (19381965) comisariada por Hoor Al-Qasimi y Salah Has-san.

\section{Palabras claves}

Modernismo artístico africano, artes visuales africanas, descolonización, historia no occidental del arte.

\section{Re-writing the History of Modernism in Africa}

\begin{abstract}
In this article, the author intends to make visible the clear intention of a generation of African cultural producers committed to model the modern history of their countries and to rewrite the History of Artistic Modernism in Africa, from a non-Eurocentric perspective. An intention that is characterized by the appropriation of the heterogeneous experience of the processes of decolonization. For this purpose, two major exhibition and academic projects are analyzed: Khartoum School: The Making
\end{abstract}


of Modern Art Movement in Sudan (from 1945 to present), co-curated by Hoor Al-Qasimi and Salah M. Hassan, and When Arts Become Liberty: The Egyptian Surrealists (1938-1965), curated by Hoor Al-Qasimi and Salah Has-san.

\section{Keywords}

African artistic modernism, African visual arts, decolonization, non-Western history of art.

\section{Re-écrivant I'histoire du modernisme en Afrique}

\section{Résumé}

Dans cet article, l'auteur a l'intention de rendre visible l'intention claire d'une génération de producteurs culturels africains de s'attacher à modéliser l'histoire moderne de leur pays et à réécrire l'Histoire du modernisme artistique en Afrique, d'un point de vue non eurocentrique. Une intention qui se caractérise par l'appropriation de l'expérience hétérogène des processus de décolonisation. A cet effet, on fait l'analyse des deux grands projets d'exposition et académiques : Khartoum School : The Making of Modern Art Mouvement in Sudan (de 1945 à aujourd'hui) avec Hoor Al-Qasimi et Salah M. Hassan comme de co-commissaires ; et When Arts Become Liberty: The Egyptian Surrealists (1938-1965), organisée par Hoor Al-Qasimi et Salah A-san.

\section{Mots clés}

Modernisme artistique africain, arts visuels africains, décolonisation, histoire de l'art non occidentale.

\section{Reescrevendo a história do modernismo na África}

\section{Resumo}

Neste artigo a autora se propõe tornar visível a clara intenção de uma geração de produtores culturais africanos empenhados em modelar a história moderna de seus países e de reescrever a História do Modernismo artístico na África, desde uma perspectiva não eurocêntrica; intenção que se caracteriza pela apropriação da heterogênea experiência dos processos de descolonização. Para tal fim, se realiza a análise de dois importantes projetos expositivos e acadêmicos: Khartoum School: The Making of Modern Art Movement in Sudan (desde 1945 até o presente) co-curada por Hoor Al-Qasimi y Salah M. Hassan e When Arts Become Liberty: The Egyptian Surrealists (19381965) organizada por Hoor Al-Qasimi e Salah Has-san.

\section{Palavras-chave}

Modernismo artístico africano, artes visuais africanas, descolonização, história não ocidental da arte.

\section{Kilkaska chi Historia Modernismo Africape}

\section{Maillallachiska}

Kai kilkaspe chi autorak nikume rurangapa suma kauari intención sug generación surkudurkuna culturales africanokuna paikunapa historia moderna paikunapa paiskuna y kilkaska historia modernismomanda artístico Africape. Sug prespectivamanda mana eurocéntrica, iuiai caracterizareme chi dueñoiai heterogeneomanda expercienci descoIonizacionmanda. Chi finmandak rurarenme agllaikuna iskai proyecto iapa importante expositivo y academicokuna: Khartoum School: The Marking of modern Art Movement in sudan (1945 manda kunaurakama) co- curada por Hoor Al- Qasimi y salah M. Hassan y When Arts Become Liberty: The Egyptian Surrealists (1938-1965) comisariada por Hoor Alqasimi y Salah Has- san.

\section{Rimangapa Ministidukuna}

Modernismo artístico africano, artes visuales africano, descolonización histórica no occidental artemanda. 


\section{Sudan en Sharjah}

Hoy en día no es posible investigar y escribir sobre el modernismo sudanés sin mencionar a Salah $M$. Hassan y sus inagotables esfuerzos para apoyar la narración de historias no occidentales del arte, especialmente del continente africano y de su país de origen.

Lo conocí en 2006. Asistimos a los eventos de apertura de la II Bienal de Sevilla, The Unhomely, comisariada por Okwui Enwezor. Éramos parte de una amplia multitud de artistas y profesionales del arte de origen africano -o de algún modo relacionados con las artes africanas- de todo el mundo. No lo conocía directamente, aunque pocos años antes visité por casualidad Unpacking Europe (2001), la exposición que él curó en el museo Boiimans van Beuningen en Rotterdam junto con Iftikhar Dadi. También conoci "NKA: Journal of Contemporary African Art", la revista que aún co-edita con Okwui Enwezor y Chika Okeke-Agulu la cual era, entonces, bastante difícil de conseguir en Europa.

El arte africano se estaba convirtiendo en tema del día, después de la Documenta XII, de Okwui Enwezor (2001), África Remix de Simon Niami (2004) y desde que Dak'Art estuvo definitivamente en el mapa de las bienales internacionales contemporáneas.

En aquel entonces, era interesante el debate acerca de la presencia (o ausencia) de artistas nacidos o relacionados con países africanos de habla árabe en el brillante y emergente contexto de las artes africanas. Y Sudán estaba casi totalmente descubierto. Sólo había un texto enmarcando el modernismo en el país, Khartoum Connections. The Sudanese Story, un capítulo del libro Seven Stories about Modern Art in Africa. El autor del texto fue Salah M. Hassan y el libro fue el catálogo de una exposición del mismo nombre organizada por la Galería Whitechapel en Londres, con motivo del Festival África 95.

Cuando nos conocimos en Sevilla, Salah fue muy generoso al compartir una larga conversación conmigo y con el historiador colombiano de arte Miguel Rojas-Sotelo, sobre su país y su historia reciente y contemporánea, desde la descolonización hasta sus relaciones con el resto del continente y con países extranjeros.
La educación intelectual y el camino creativo de Salah - como uno de los muchos artistas, escritores, activistas e intelectuales que crecieron en Sudán durante la descolonización-comenzó en el contexto de las academias de arte del país, que se desarrollaron con una connotación colonial muy fuerte inicialmente (La primera Escuela de Arte que se inauguró a principios de 1930: el Departamento de Arte del Gordon Memorial College, que evolucionó a la Escuela de Diseño en 1946, con la complicidad de los británicos y otros expatriados occidentales que desempeñaron un papel en el establecimiento y desarrollo de los currículos). Pero también fue crucial el vibrante contexto de los años setenta en Sudán, donde el Partido Comunista se convirtió en una organización muy fuerte y de mente abierta, catalizador de un movimiento cultural progresista y vibrante más amplio que involucraba todos los aspectos de los estudios humanísticos y la cultura en general.

Esta premisa es necesaria para enmarcar el campo de los estudios sobre el Modernismo Sudanés y específicamente sus artes visuales. La Khartoum School: The Making of Modern Art Movement in Sudan (desde 1945 hasta el presente) es, por lo tanto, un capítulo sobresaliente de este activismo, que involucra a toda una generación de productores culturales sudaneses, que crecieron dentro y fuera de Sudán, modelaron la historia moderna del país y experimentaron la descolonización como un momento crucial de su desarrollo individual y colectivo.

Co-curada por Hoor Al-Qasimi y Salah M. Hassan, La Khartoum School es una pieza revolucionaria de la historia y una visión muy participativa y vibrante, de las ideas, tensiones, experimentos, opiniones e intentos de empujar los límites de las culturas, que surgió en Sudán desde la segunda mitad del siglo $X X$. El proyecto completo incluye la exposición en Shariah Art Foundation hasta mediados de enero de 2016, la publicación de un libro y la conferencia sobre identidad y el hacer de la modernidad: Recordando los años 60 y 70 en Sudán (que fue organizado en abril de 2015 y apoyada por Sharjah Art Foundation en colaboración con el Cornell's Institute for Comparative Modernities).

La Khartoum School fue configurada por primera vez por el pintor guyanés y crítico de arte Denis 

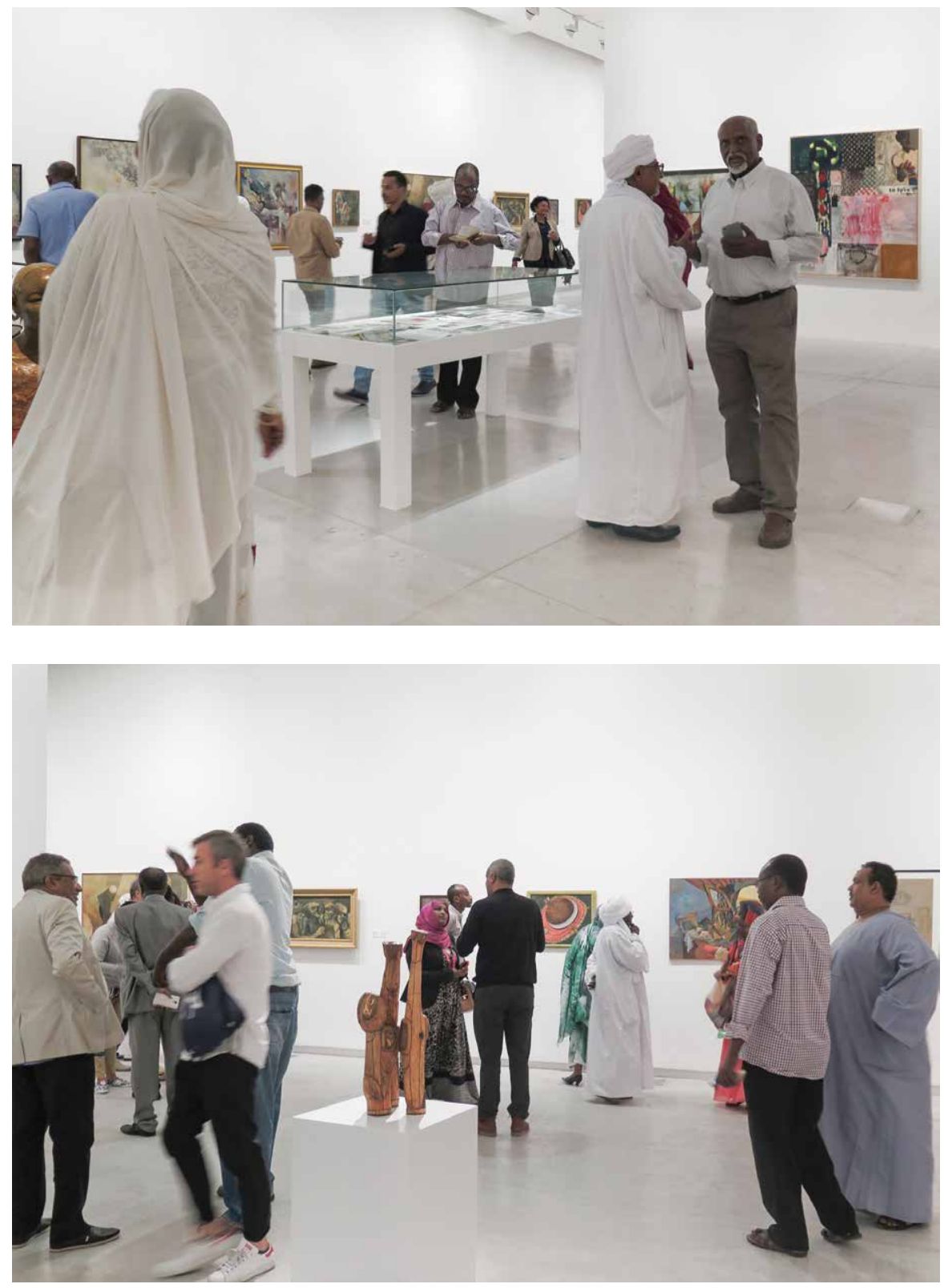

Opening, Khartoum School 


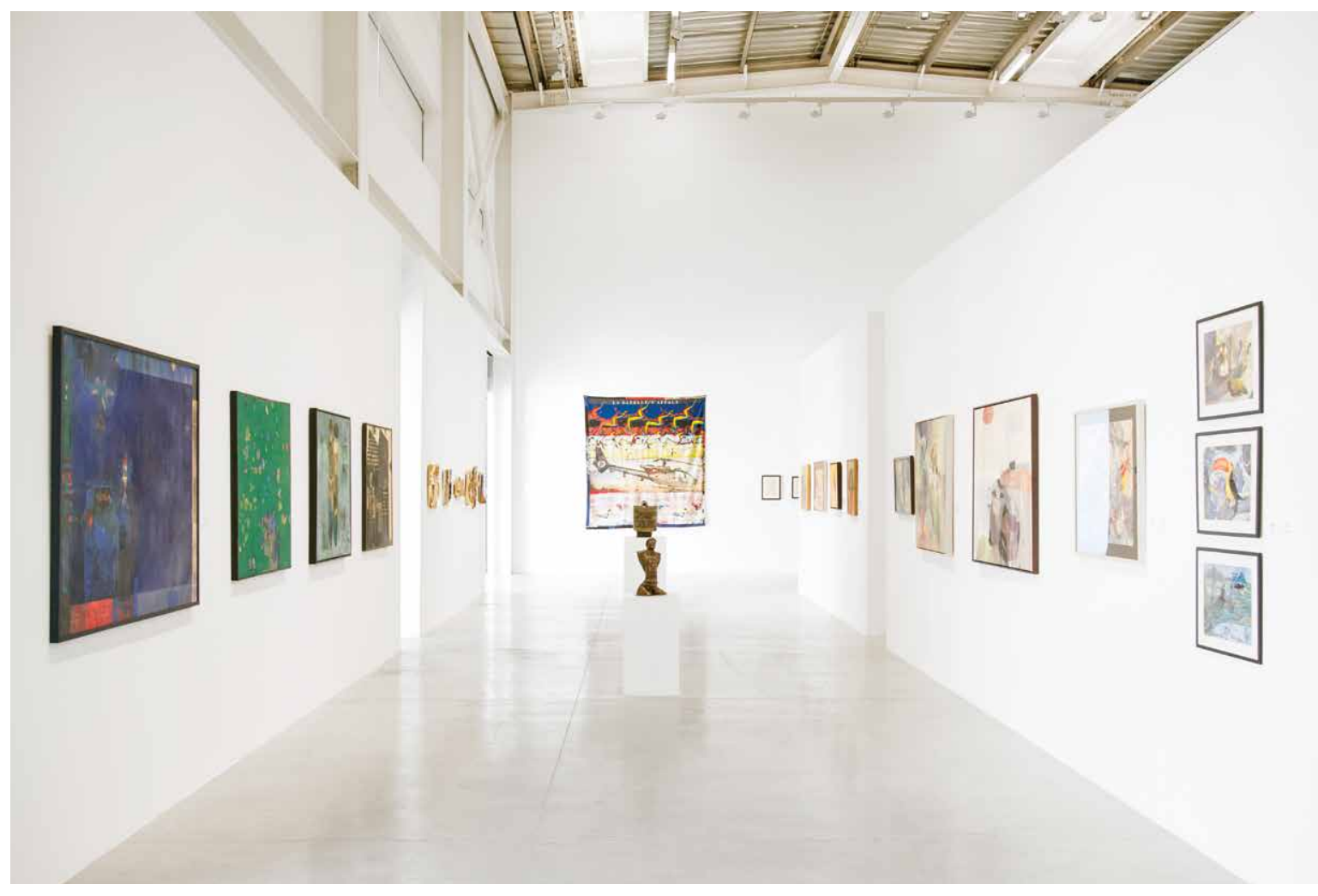

Khartoum School

Williams, quien enseñó en el Colegio de Bellas Artes y Artes Aplicadas de Khartoum en los años 60. Esta convención de denominación se ha repetido como una definición del movimiento modernista sudanés, incluso sin ser apropiada como un nombre de grupo o un manifiesto por cualquier artista. Hoor Al-Qasimi y Salah M. Hassan decidieron usar este término para denotar el desarrollo del campo de las artes visuales en Sudán durante el denominado "Siglo Corto" y para señalar lo crucial que fue para muchos artistas la definición y búsqueda de lo que era el arte "sudanés". Esto, sin promover alguna connotación nacionalista; en cambio, los curadores miraron cómo la formación de una idea nacional del movimiento de arte moderno en Sudán estaba de acuerdo con el desarrollo de un discurso decolonial en el país.

Los capítulos de la exposición de este amplio proyecto de investigación se establecieron en los espacios de la Shariah Art Foundation a través de diferentes muestras.
La bellamente concebida e instalada muestra, Amir Nour: La brevedad es el alma del ingenio (una exposición retrospectiva, de 1965 al presente) es una de las primeras retrospectivas de medio siglo de trabajo del artista conceptual sudanés, residente en Estados Unidos, Amir Nour. "La brevedad es el alma del ingenio," hace referencia a un proverbio que Amir Nour utiliza a menudo para "describir su práctica y su divergencia con ideas minimalistas," como declaran los curadores, como un intento de romper con la tradición "cool" del minimalismo occidental. Un verdadero modernista cosmopolita, Nour estudió en la Khartoum School of Fine Arts en la década de 1950. Luego se trasladó a Londres para su diploma en la Slade School of Fine Art y el Royal College of Art en la década de 1960 y, finalmente, asistió a la Universidad de Yale, con una beca Rockefeller antes de obtener una cátedra de Bellas Artes Aplicadas en Chicago. Desde los años sesenta utilizó la estética minimalista y africanista, transformando de hecho los límites del minimalismo como un movimiento global 


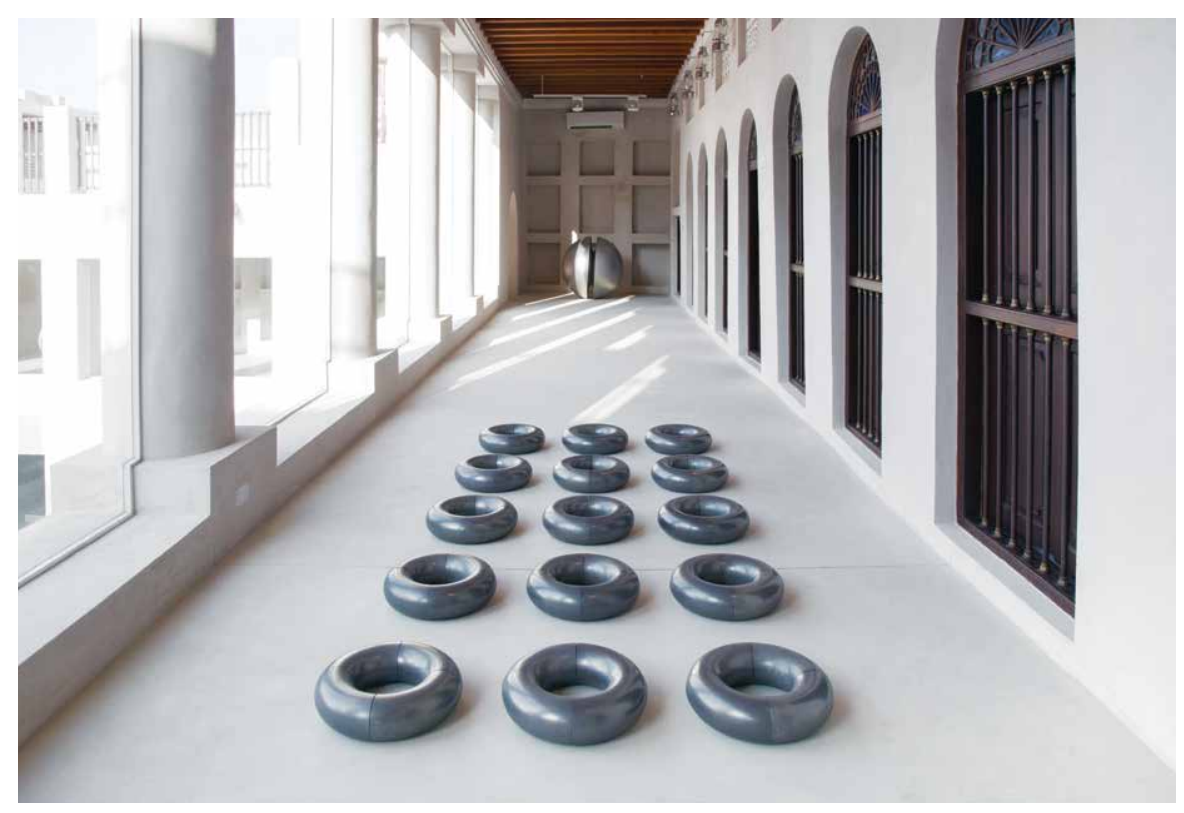

Amir Nour, La brevedad es el alma del ingenio, 2015

que incluyó no sólo a artistas como Carl Andre, Dan Flavin, Donald Judd, Sol LeWitt y Robert Morris, entre otros escultores y pintores, sino también a figuras seminales tales como Rashed Araeen — pakistaní de nacimiento-y Nour mismo. La exposición se extiende desde las esculturas más conocidas, impecablemente instaladas, hasta dibujos y pinturas, mostrando el firme vocabulario de formas geométricas de Nour, que hace referencia a la arquitectura del norte del Sudán, así como al trabajo de los artesanos en los mercados aldeanos de Sudán y a los métodos e ideas del minimalismo occidental.

La exposición individual de Kamala Ibrahim Ishaq, Woman in crystal cube, presenta y reseña la totalidad del corpus de su trabajo y es la primera retrospectiva de una de las principales artistas pioneras e influyentes pintoras modernistas en Sudán. Kamala, es otra figura culturalmente sofisticada, internacional de la escena del arte sudanesa, que desde el principio de los años 60 fue educada en Sudán y en el Reino Unido y viajó extensivamente. A mediados de la década de 1970, cofundó la Chrystal School, con sus dos antiguos alumnos, Muhammad
Hamid Shaddad y Naiyla al Tayib. Los años 70 fueron para Sudán los años de la descolonización y también del desarrollo de nuevas tensiones e investigaciones dentro de la escena artística local, evolucionando especialmente como un rechazo de los estilos, procesos y visión de la Khartoum School, de carácter modernista y definitivamente orientada al Sudán. En 1978 Kamala firma, junto con Shaddad y Tayib, el Manifiesto Cristalista (Al-bayan al-kristali), que presenta una visión que desafía explícitamente la visión islámica y masculina dominante del arte de la establecida Khartoum School. Para los Cristalistas, el universo es como un cubo de cristal: transparente y que cambia constantemente según la posición del espectador. Su perspectiva apuntaba a adoptar una mirada existencialista de vanguardia, más parecida a la estética europea. Es relevante subrayar cómo la educación de Kamala en Londres contribuyó para su acercamiento a las obras de artistas como William Blake (a quien ella se refiere en muchas de sus obras) y Francis Bacon. El título de la exposición está inspirado en la exposición de Kamala, Women in Crystal Cubes, realizada en 1978, que exploró la relación con la cultura sudanesa (y oriental 
africana) de Zār: ceremonias femeninas de posesión de espíritus de las que fue testigo y las cuales estudió posteriormente.

La exposición está dominada por poderosos dibujos y pinturas que presentan los rostros y figuras distorsionadas de las mujeres, a menudo de carácter monocromas. Pero también, los curadores decidieron mostrar el archivo de la artista, con sus obras gráficas realizadas para publicaciones de poetas, escritores e intelectuales sudaneses.

Lo que podría considerarse como lo principal de la muestra es una amplia panorámica de la producción artística sudanesa desarrollada a lo largo de la segunda mitad del siglo XX. Organizada en diferentes secciones, la exposición se abre con el Cuaderno Penitenciario de Ibrahim El-Salahi (1976), presentado junto con una larga entrevista grabada en 2014: la voz de Ibrahim narra cada página del diario. Hoor Al-Qasimi y Salah M. Hassan ya han trabajado juntos en torno a la narración de la historia de los capítulos centrales de la Historia del Arte del Siglo XX del Mundo Árabe, y la gran retrospectiva de Ibrahim El Salahi (que tuvo lugar primero en Shariah, en mayo de 2012, y en la Tate Modern de Londres a partir de julio de 2013) fue sin duda el primer paso hacia esta cooperación, que llevó a la Shariah Art Foundation a apoyar plenamente la exposición. Es por eso que pienso que es muy importante abrir esta innovadora exposición con el trabajo de un artista histórico como El-Salahi, quien volvió a encontrar su lugar en la historia del arte gracias a la gran retrospectiva de la Shariah Art Foundation, organizada en 2012.

Los dos curadores viajaron a Sudán y a otros países occidentales para investigar y establecer el marco conceptual de la exposición y seleccionar los artistas, sus obras y los diversos materiales multimedia conservados en archivos privados alrededor del mundo.

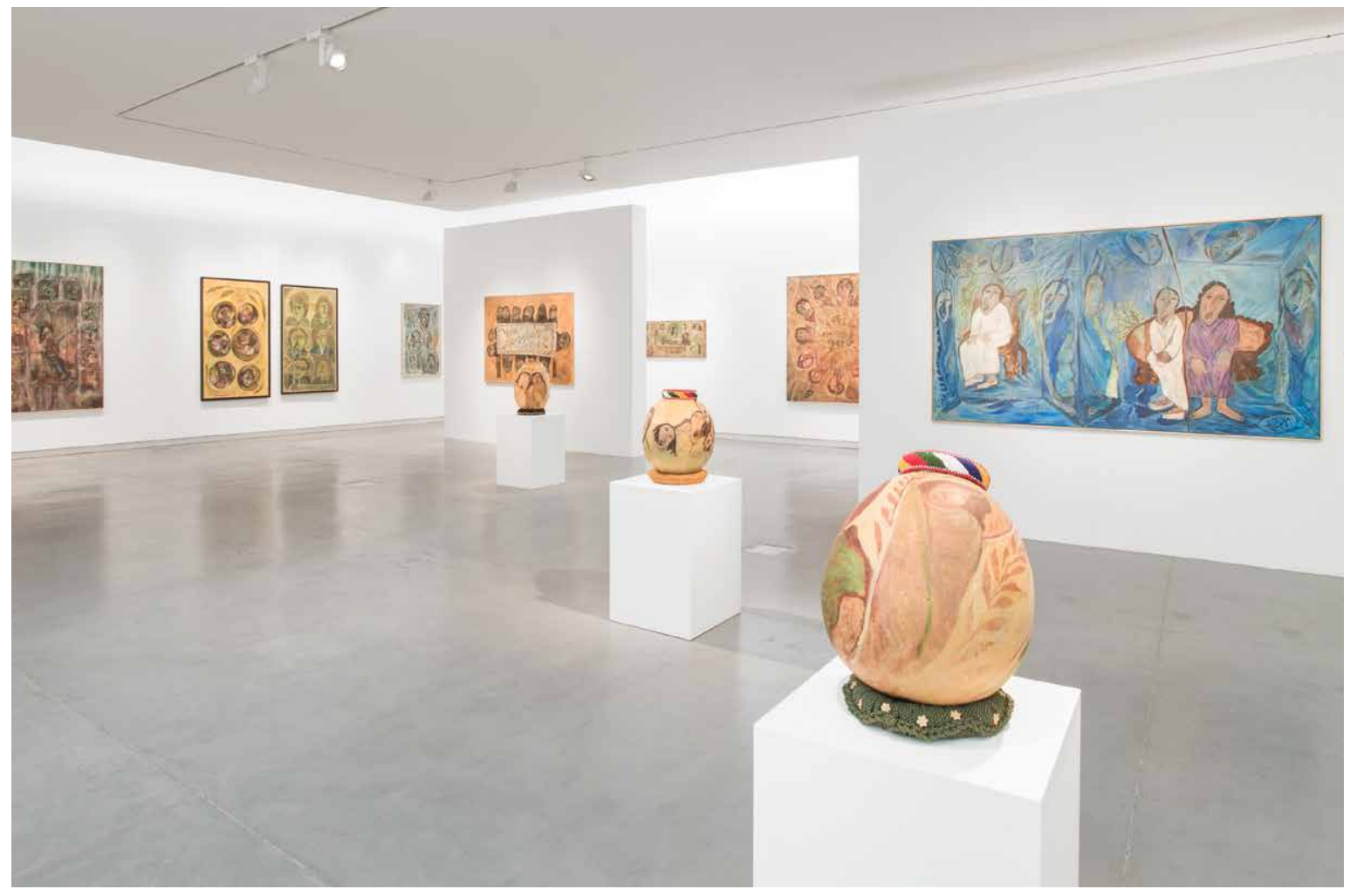

Kamala Ibrahim Ishaq Woman in crystal cube. 

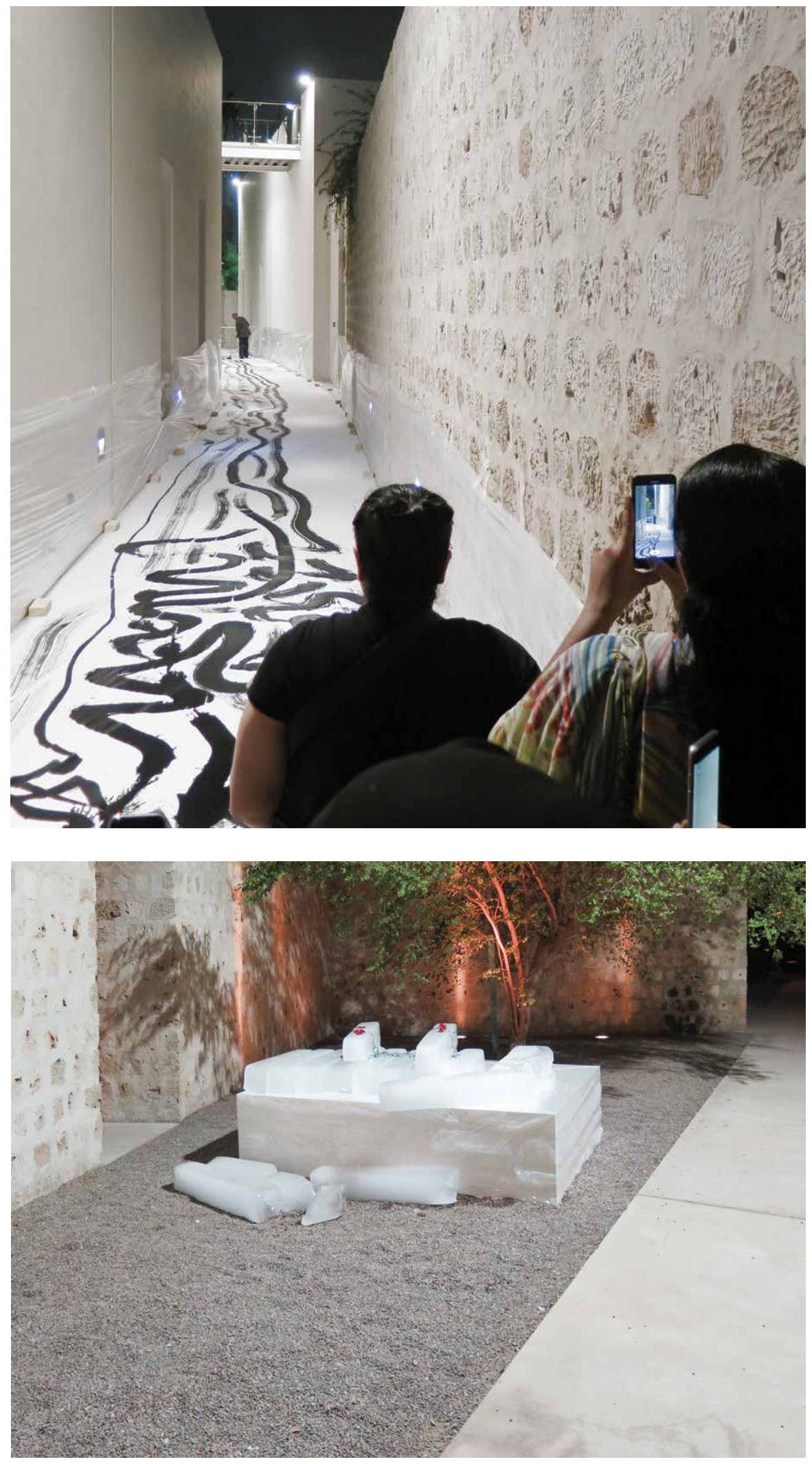

Arriba: Mohammed Hamid Shaddad, recreación.

Abajo: Hassan Musa, El Picnic del Artista. 
Según ellos, "en vez de ofrecer una presentación cronológica, la exposición se organiza en torno a figuras, grupos y movimientos fundacionales, cada uno ofreciendo una fuente de ideas y un vocabulario visual que constituye una representación colectiva del arte moderno y contemporáneo en Sudán". La exposición tiene, por lo tanto, una estructura fluida, que converge en torno a temas específicos: La "Khartoum School", Pioneros y Revolucionarios, El Giro conceptual, Abstracciones Caligráficas (Madrasad Al-Wahid - The School of the One); Imaginando la Modernidad: Fotografía y Cine, Dibujos animados, Prensa y Medios de Comunicación, llustración y Literatura Infantil; La actual escena del arte en Sudán (desde mediados de la década de 1980 hasta la de 1990). Una gran encuesta, si bien en leguaje experto, parece centrarse principalmente en los medios y técnicas tradicionales (la pintura y alguna escultura), dan una perspectiva sobre el cine y el lenguaje audiovisual (gracias a la presencia de las obras de Sudanese Film Group y Sudan Film Factory).

El evento de apertura fue también la ocasión para que una gran comunidad de artistas sudaneses de diferentes generaciones (radicados en Sudán y en el extranjero) pueda reunirse en Sharjah, y en algunos casos después de varias décadas. Esta reconstrucción de la historia a través de la implicación personal de muchos individuos (cada artista invitado o, en algunos casos, pariente, contribuyendo con la apertura de sus estudios y archivos, narran historias que han sido esenciales para reconstruir el panorama), dio al evento una dimensión que va mucho más allá del montaje relativamente simple de una exhibición: una comunidad que se reconoce y finalmente es reconocida por la historia como parte de todo un sistema de ideas y acontecimientos. En este sentido, el proyecto curatorial (con su investigación, conferencias y publicaciones) tiene un impacto real en la comunidad artística sudanesa (así como en los artistas más jóvenes, que ahora están activos dentro y fuera del país y finalmente pueden verse como parte de una colectividad). Por su parte, la apertura del evento fue un momento emocionante que culminó con la mesa redonda final, en la que Salah Hassan dirigió una conversación con Hassan Musa y Mohamed Hamid Shaddad. Los dos artistas compartieron con la multitud su impresión sobre la producción estética y la investigación artística y la manera en que su perspectiva transformó el acercamiento a la Khartoum School.

Musa y Shaddad, son artistas que también presentaron dos eventos especiales, que ocurrieron durante los días de la inauguración: Mohammed Hamid Shaddad, un miembro de fundación del grupo de Cristalistas, recreó la exposición del hielo de 1978, repitiendo una acción famosa en la que dos bloques del hielo se dejaron derretir en el espacio de la exposición. Hassan Musa realizó El Picnic del Artista, en el que interpreta el acto de pintar como un viaje, esencial, por lo tanto, al proceso más que al resultado final.

The Khartoum School: The Making of the Modern Art Movement in Sudan (1945 - present) ${ }^{1}$ Exposiciones: 12 noviembre de 2016 -

14 enero de 2017 Edificio GH \& P SAF Art Spaces, Shariah Art Foundation, Shariah

\section{Arte y libertad: reescribiendo Historia del Arte en el Cairo}

Cuando el 24 de marzo de 1938 el poeta futurista Filippo Tommaso Marinetti presentó su conferencia La Poésie Motorizé en el club Essayistes de El Cairo, no podía imaginar que su perspectiva conservadora y pro-colonial iba a chocar con las tensiones, visiones y necesidades de una nueva generación de artistas e intelectuales egipcios. Georges Henein (1914-1973), miembro del club, se levantó y atacó violentamente a Marinetti y la cultura fascista que encarnó: la presencia del viejo escritor en El Cairo —el padre conservador del futurismo y muy cercano a las ambiciones de Mussolini de Expansión en Libia y el Cuerno de África- no podía dejar de estar conectado a las guerras fascistas italianas en el continente y en general al imperialismo europeo.

El evento dejó un legado en El Cairo, que fue mucho más allá de la simple confrontación entre

\footnotetext{
1 Co-curada por el Director de la Fundación de Arte de Shariah, Hoor AI Qasimi y el Dr. Salah M. Hassan, Profesor de Goldwin Smith Profesor de Diáspora Africana e Historia del Arte Africana y Cultura Visual en el Centro de Estudios e Investigaciones Africanas y Departamento de Historia del Arte y Estudios Visuales de la Universidad de Cornell.
} 


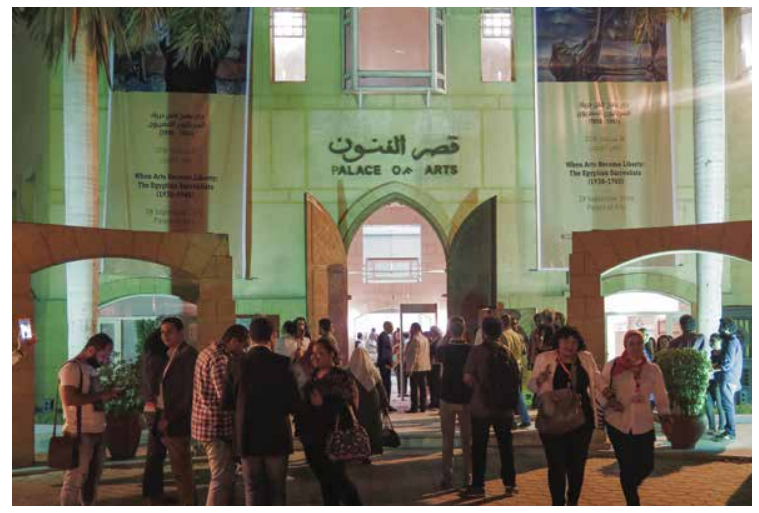

The Palace of Arts in Cairo.

dos intelectuales con orígenes políticos diferentes y dos generaciones distantes. Henein, un escritor joven, progresista, sofisticado y cosmopolita que ya había presentado las ideas del Surrealismo francés en Egipto desde principios de la década de 1930, abandonó la sala con la intención de crear un grupo independiente. El 22 de diciembre de 1938, fue el iniciador de Vive l'Art Dégénéré, un manifiesto firmado por otros 40 nombres de la escena progresista de El Cairo y distribuido en árabe y francés en la ciudad y en el extranjero. $\mathrm{Si}$ Europa ardía bajo los regímenes del nacismo y el fascismo, que amenazaban la libertad de expresión y la existencia misma del arte, la respuesta de la nueva intelectualidad egipcia consistía en abordar la conciencia de los intelectuales y su papel en la creación y el intento de los regímenes por censurar la crítica y el libre pensamiento.

Utilizando como desencadenante la exposición Entartete Kunst (arte degenerado) realizada en Múnich en 1937, el manifiesto de Vive l'Art Dégénéré fue una declaración cultural para Egipto y para Occidente. Europa se está derrumbando bajo regímenes conservadores; la escena cultural en Egipto debe tomar una posición contra esos regímenes y las culturas que proponen; el papel de los artistas del mundo no occidental es desfigurar el conservadurismo de la nueva Edad Media que se alza en el mismo corazón de Europa y oponerse a su propagación global. Además de leer las líneas y superponer este discurso a la Europa de esta segunda década del siglo XXI, es necesario recordar históricamente que en el México posrevolucionario, en el mismo 1938, se propuso una

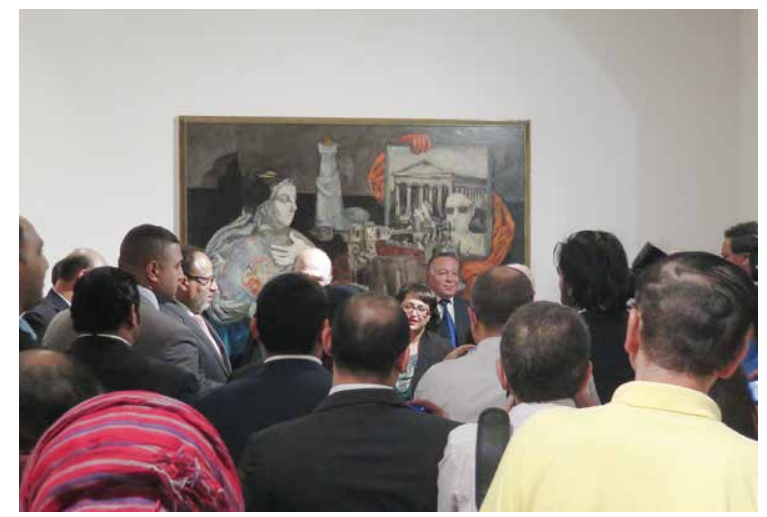

Image from the opening of the exhibition.

posición muy similar en el Manifiesto por un Arte Independiente y Revolucionario, firmado por el pintor muralista mexicano Diego Rivera, junto con León Trotsky (por entonces refugiado en México de las manos asesinas de Stalin) y André Breton.

Pocos meses después, en marzo de 1939, se lanzó el Jama'at al-Fann Wa al-Hurriyyah (Grupo de Arte y Libertad) junto con un boletín llamado Art et Liberté, circulando en francés. Junto con George Henein, Ramses Younan, Fouad Kamel, Anwar Kamel, Edmond Jabes y Kamel Telmisany, como parte del grupo activo hasta 1945; con grandes exposiciones organizadas bajo el nombre de Ma'arid al-fann al-hur (Exposiciones de Arte Libre) y la edición de algunas publicaciones periódicas: Don Quichotte, Part du Sable y periódicos árabes como Al Risalah (El Mensaje), Al Majallah Al Jadidah (La Nueva Revista) y Al-Tatawwur (Evolución). Si la estética y el lenguaje artístico del grupo no pueden definirse como estrictamente surrealistas, sino a menudo relacionados con algún tipo de expresionismo realista y mágico, es claro el vínculo con posiciones culturales progresistas (del trotskismo al estalinismo), con el liberalismo, así como con los enfoques de la vanguardia moderna europea en la producción teórica y política que se extendió a través de las diversas publicaciones.

La historia de la experiencia pionera de Arte y Libertad es el punto de partida para la primera y mayor exposición sobre el surrealismo egipcio, comisariada por Hoor Al-Qasimi y Salah Has-san: When Arts Become Liberty: The Egyptian Surrealists (1938-1965). La exposición fue abierta en el otoño 


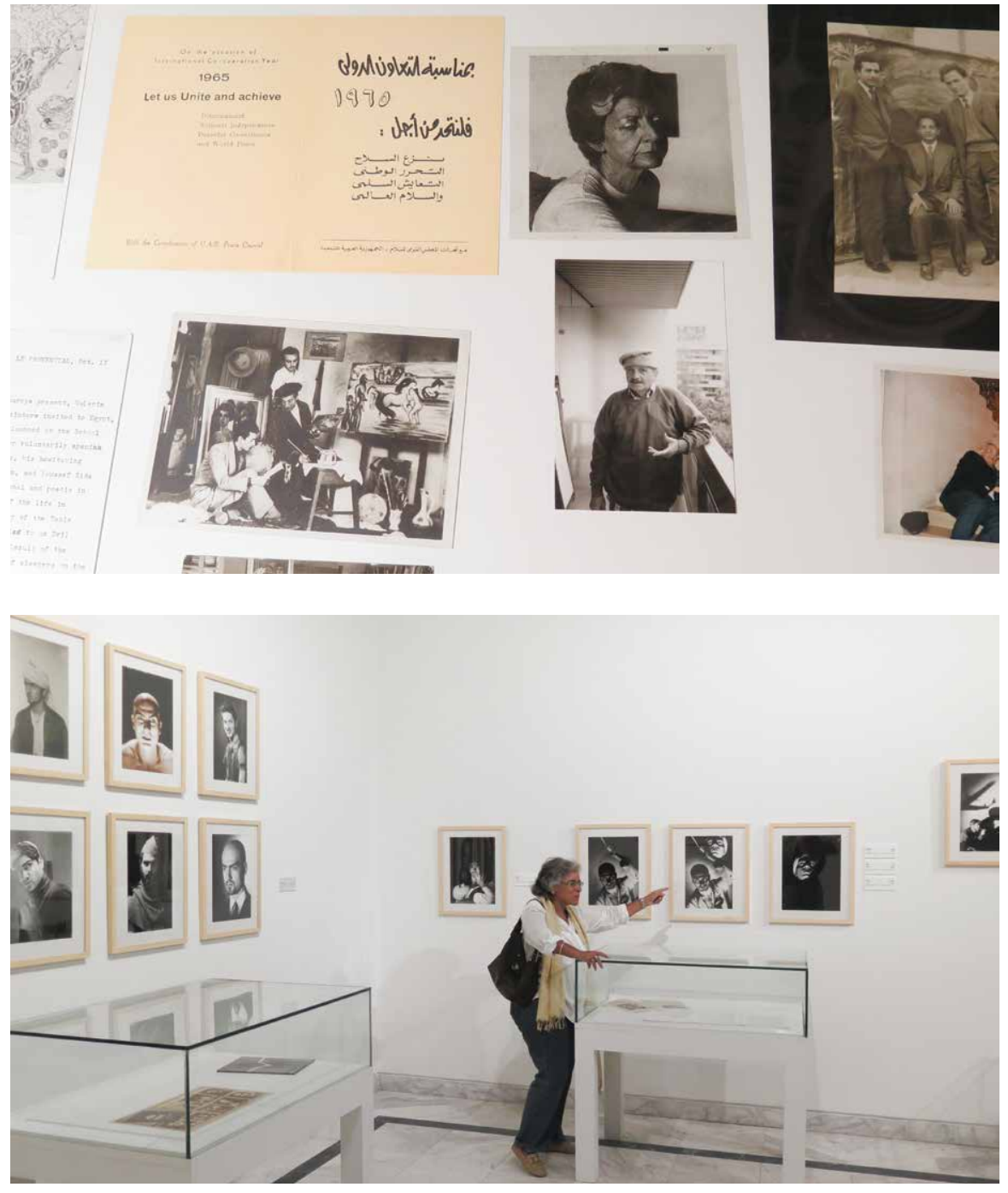

Arriba: Detalle de materiales de archivo.

Abajo: Vista general de la sección dedicada a Van-Leo. de 2016 en el Palacio de las Artes de El Cairo (Egipto) y actualmente visible en el Museo Nacional de Arte Moderno y Contemporáneo, Corea (28 de abril - 30 de julio de 2017). Con la clara intención de reescribir la Historia del Modernismo desde una perspectiva no eurocéntrica, la exposición desvela la trayectoria de los movimientos artísticos de vanguardia en Egipto desde los años 30 hasta comienzos del siglo XXI, desvelando los vínculos con otros grupos activos en Occidente, el compromiso con las organizaciones globales, no coloniales, progresistas y marxistas, situando a Egipto en el centro de una compleja red de relaciones, intercambios e influencias.
Las 140 piezas presentadas en la exposición muestran también las obras de otros artistas influenciados por Art and Liberty, desde mediados de los años cuarenta hasta comienzos de los años sesenta, como el Contemporary Art Group (que incluyó a Abdel Hadi El-Gazzar, Kamal Youssef entre otros) y las obras de artistas que trabajan independientemente o en relación con los grupos y que expresan investigaciones visuales similares. La selección de 30 fotos del retratista Van-Leo (1920-2002), es un verdadero descubrimiento en este sentido: muestra una pequeña parte de su enorme colección de 15.000 fotos y 250.000 negativos, archivados en la American University (el 
Cairo libros raros y colecciones especiales), una colección apena conocida.

Esta exposición incluye también una sección dedicada a la vida futura de los surrealistas, con el trabajo de los artistas de Egipto que, a partir de 1960 en adelante, han seguido enfoques similares y el compromiso con las ideas de arte y libertad.

When Arts Become Liberty, es el resultado de 7 años de investigaciones que involucraron la visita a colecciones privadas y públicas, casi desconocidas e intactas durante años. Salah M. Ha-ssan y Hoor Al Qasimi colaboraron con el archivo de museos, coleccionistas privados en Egipto y en el extranjero, con el archivo personal de muchos artistas egipcios y reconstruyeron un hito que ha sido olvidado o descuidado durante décadas. La participación de las instituciones egipcias fue un elemento clave para los curadores, que acordaron la apertura del itinerario de la exposición en El Cairo, donde los egipcios podrían visitar y redescubrir su propia historia del modernismo.

La muestra siguió a la conferencia internacional The Egyptian Surrealists in Global Perspective, que tuvo lugar en la American University de El Cairo, en noviembre de 2015 y contó con presentaciones de académicos egipcios e internacionales.

La conferencia y la exposición no son la primera cooperación entre Hassan y Al Qasimi, que trabajan desde décadas para desvelar la Historia del Arte desde una perspectiva no occidental, a menudo en estrecha colaboración. En abril de 2016, la Shariah Art Foundation patrocinó y organizó la Modernity and the Making of Identity in Sudan: Remembering the Sixties and Seventies. En 2012, la exposición Ibrahim El-Salahi: A Visionary Modernist que destacó la obra del artista sudanés Ibrahim El-Salahi. Un gran programa sobre el modernismo en Sudán se abrió en Shariah en noviembre de 2016.

\section{Detalles}

When Arts Become Liberty: The Egyptian Surrealists (1938-

1965), comisariada por Hoor Al Qasimi, director de la Sharjah Art Foundation y Salah M. Hassan, profesor de Goldwin Smith y director del Instituto de Modernidades Comparadas de la Universidad de Cornell.
La Shariah Art Foundation organizó y financió la Exposición en colaboración con el sector de Bellas Artes del Ministerio de Cultura de Egipto y la Universidad Americana de El Cairo (AUC).

La muestra se inauguró en el Palacio de las Artes de El Cairo (Egipto), el 28 de septiembre de 2016 hasta 28 de octubre de 2016, y pronto viajará a otros lugares para ser exhibida, antes de concluir en los espacios de Shariah Art Foundation en 2018. Como parte de este proceso, la Shariah Art Foundation, lanzará una publicación bilingüe (árabe-inglés) en dos volúmenes. El primero incluirá ensayos de los participantes en la conferencia y una introducción completa de Hassan y Al Qasimi; el segundo, incluirá reimpresiones de los principales documentos relacionados con el movimiento surrealista egipcio. 
Imágenes de algunas obras de la exposición: When Arts Become Liberty: The Egyptian Surrealists (1938-1965)

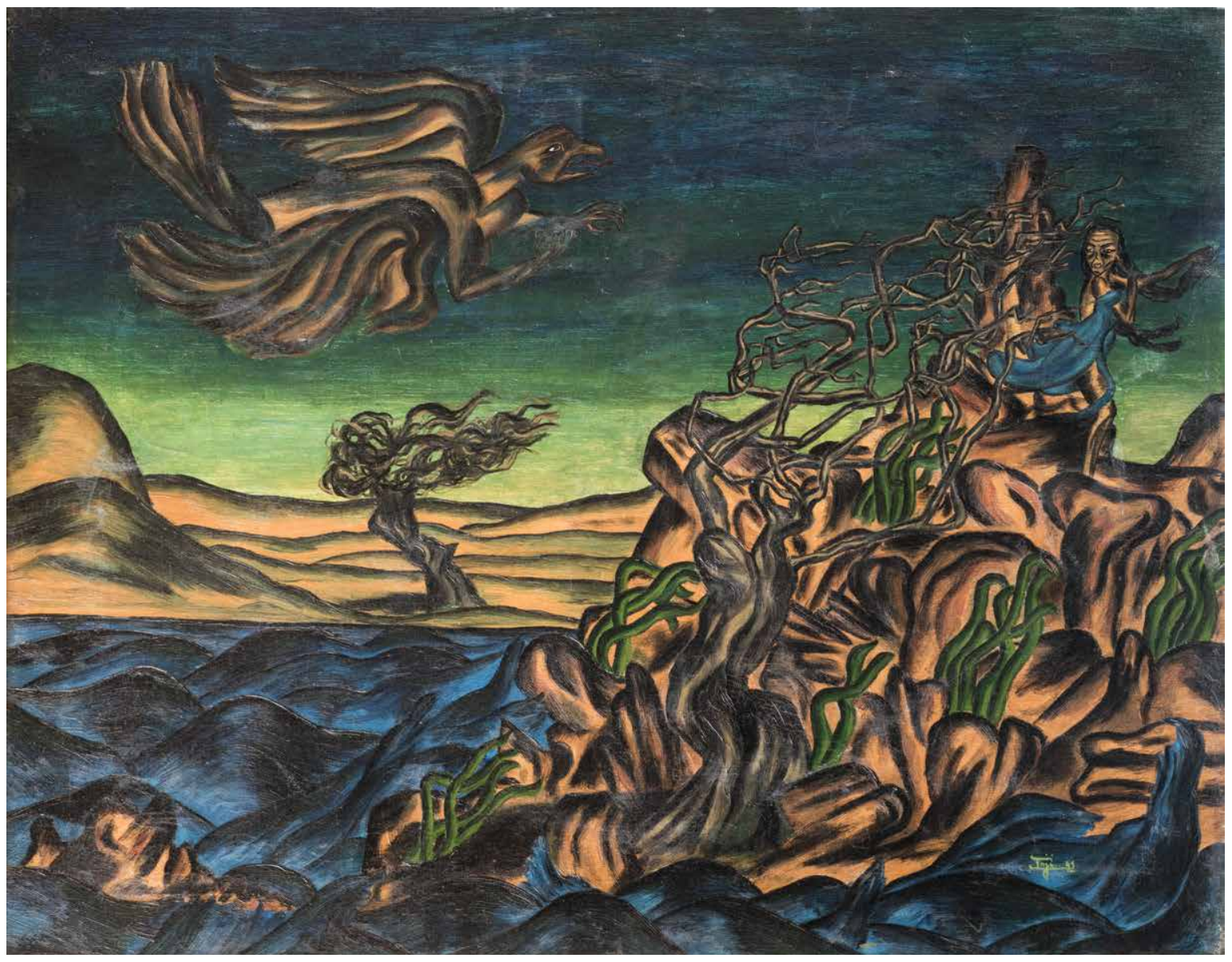

Inii Efflatoun, The Girl and the Beast, 1941, Oil on canvas, 70 X $55 \mathrm{~cm}$. Courtesy Museum of Inji Efflatoun, Sector of Fine Arts, Ministry of Culture, Egypt. 


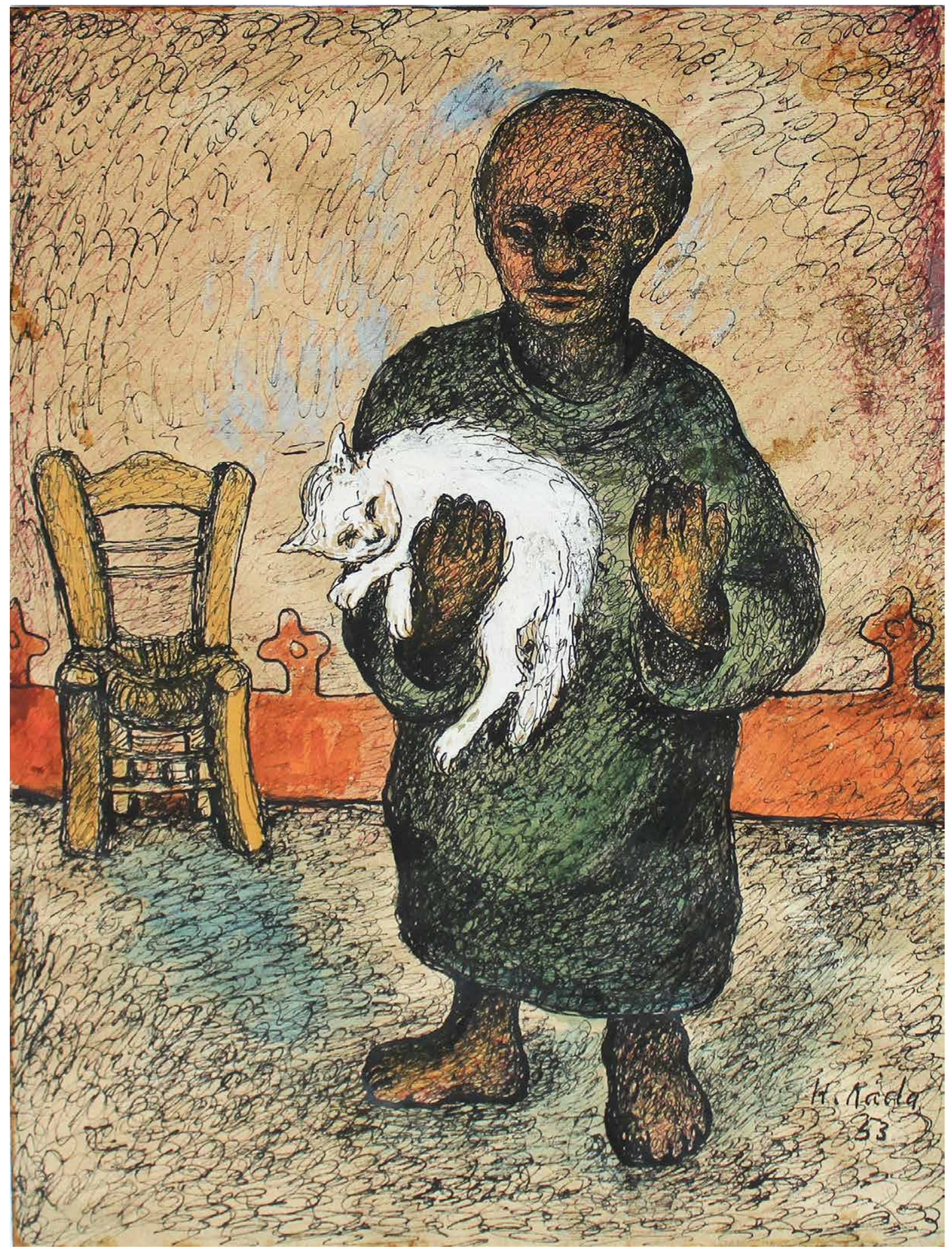

Hamed Nada, Man with Cat, 1953, Mixed Media on paper, 35.5 × $28 \mathrm{~cm}$. Shariah Art Foundation Collection. 


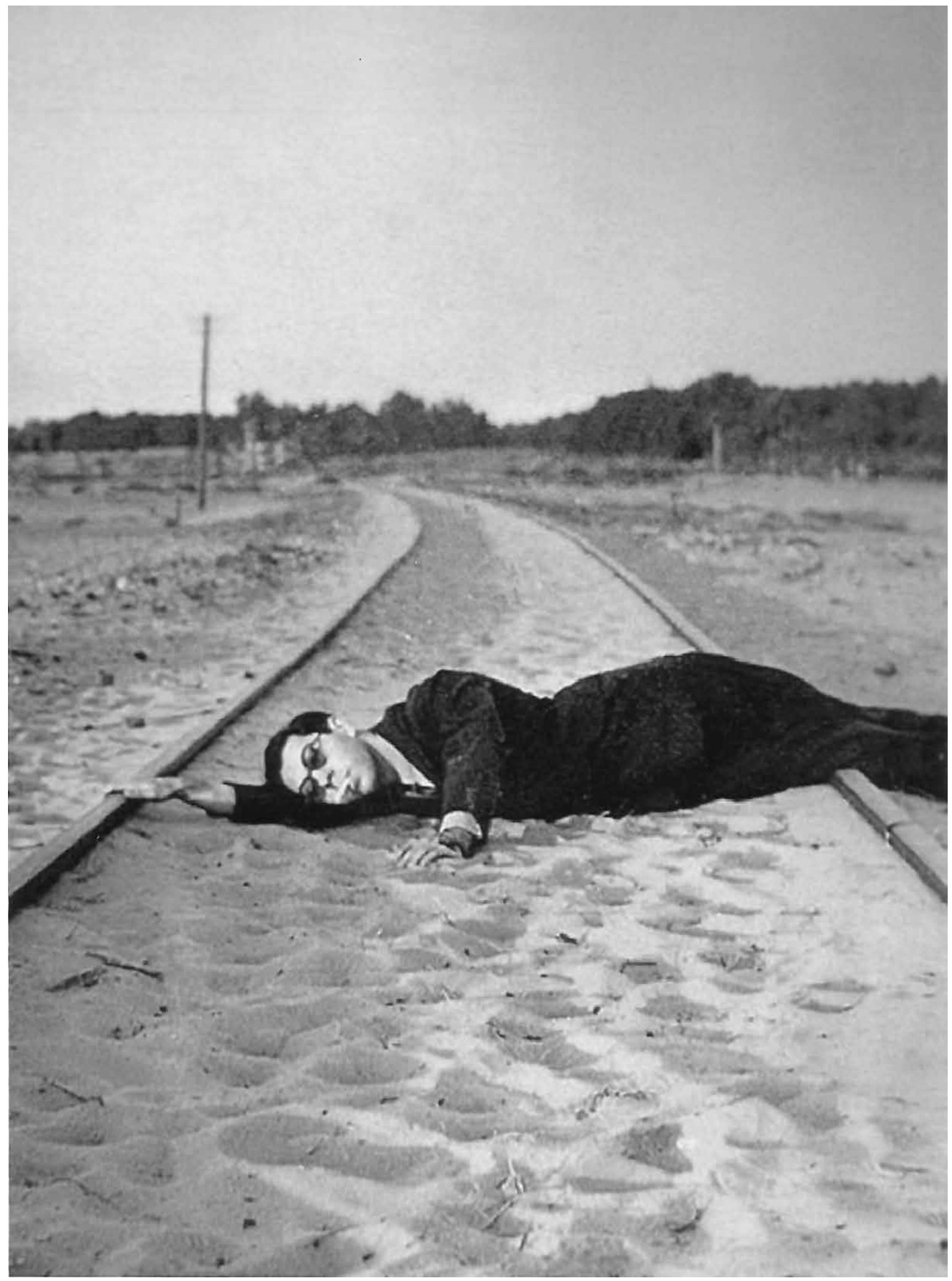

Georges Henein. Photography by Boula Henein. 


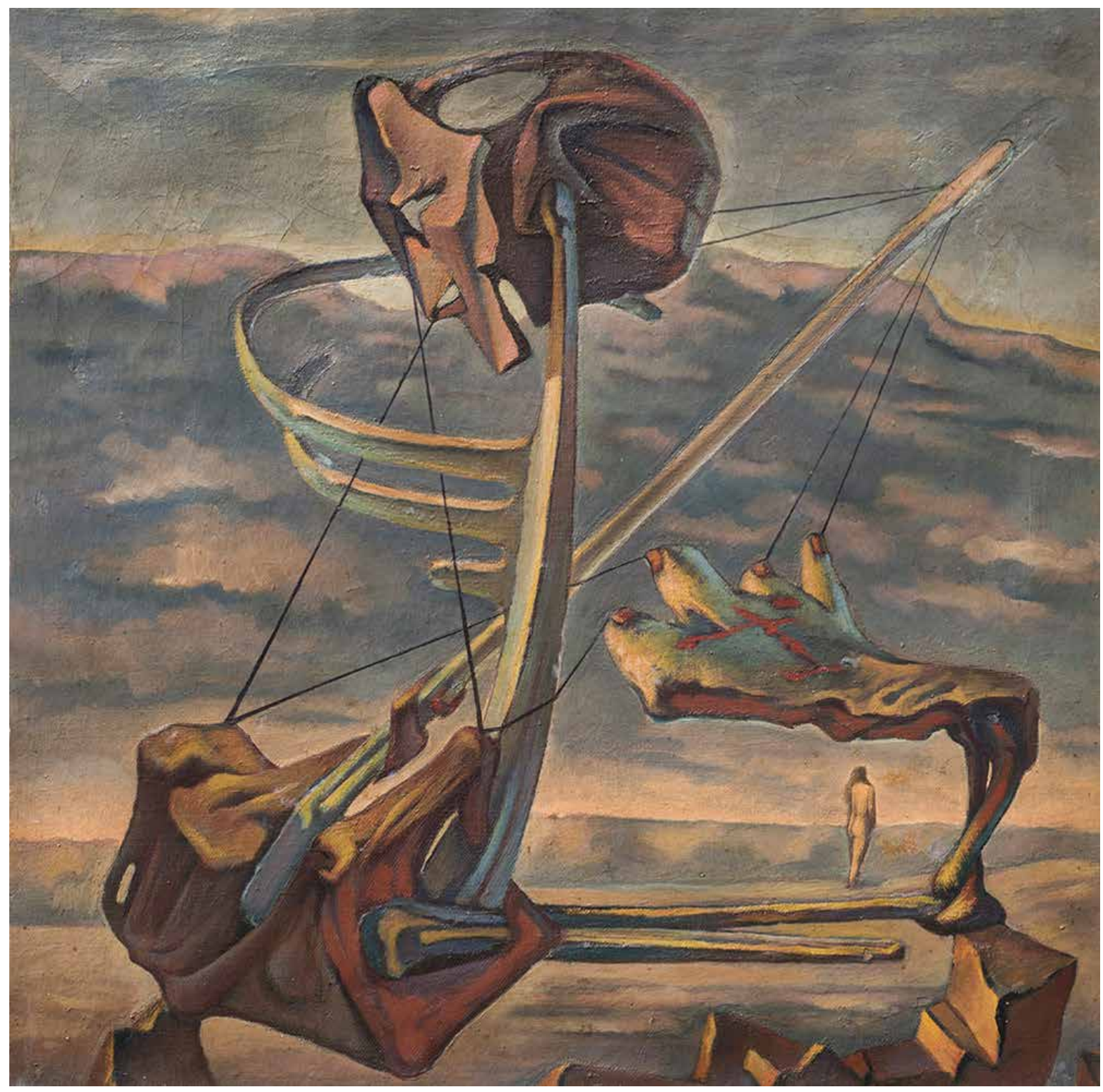

Ramses Younan, Nature Loves a Vacuum, 1944, Oil on canvas, 66 ×66 cm. Courtesy of the Museum of Modern Egyptian Art, Sector of Fine Arts, Ministry of Culture, Egypt. 


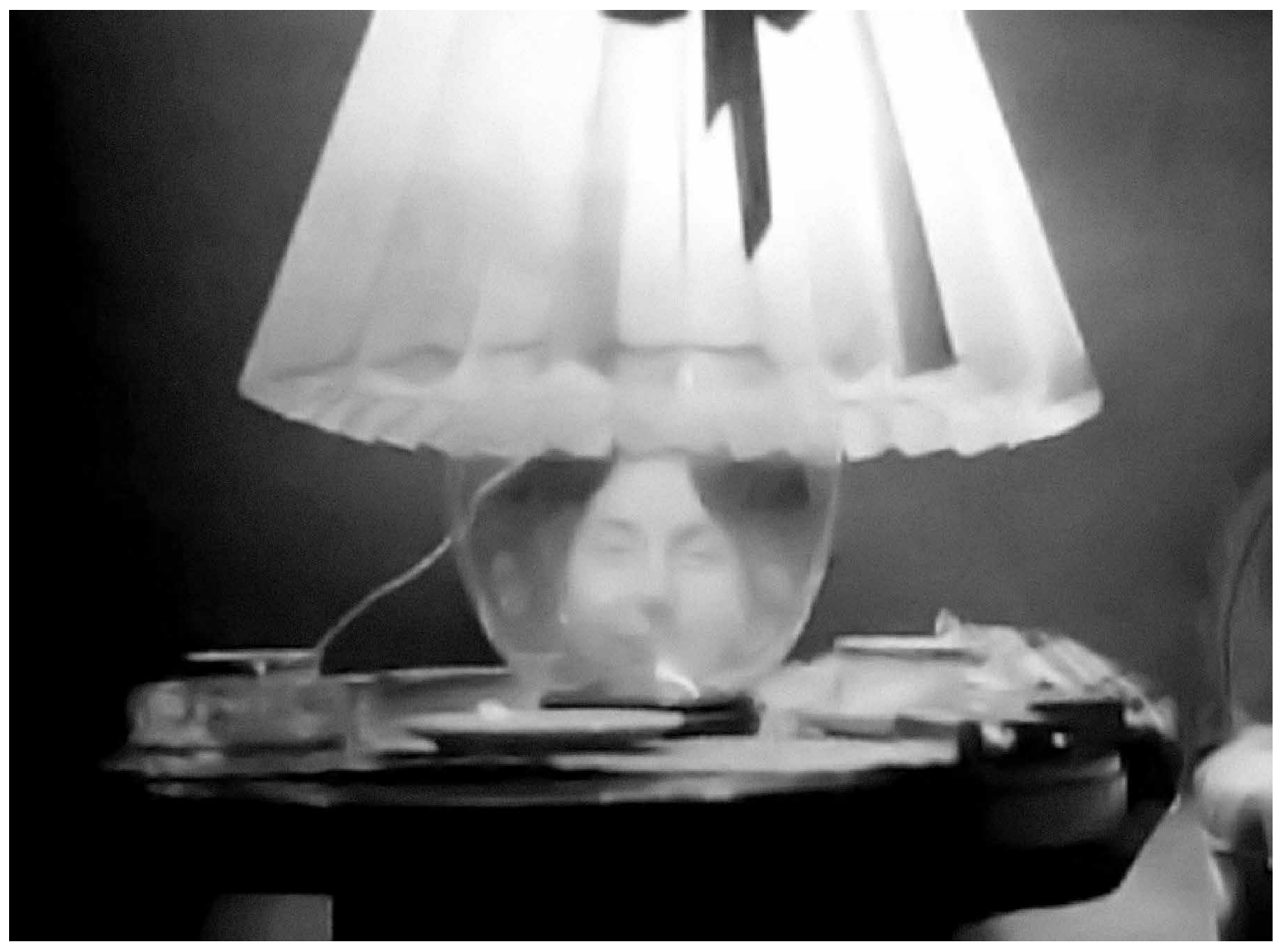

Gulperie Eflatoun. Photography by Georges Henein. 


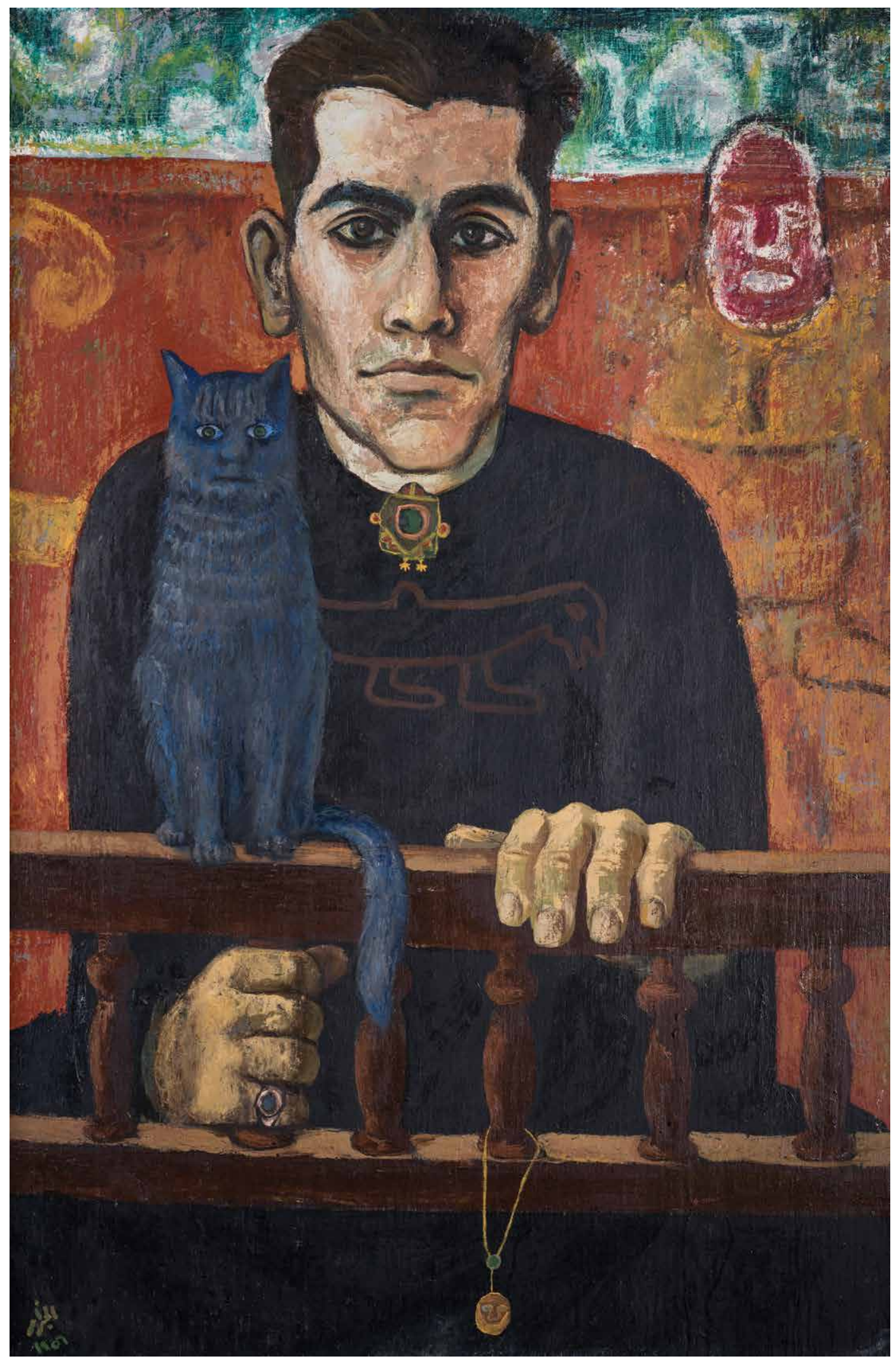

Abdel Hadi El-Gazzar, Man and Cat, 1956, Oil on plywood, 90 x $127 \mathrm{~cm}$. Courtesy of Museum of Modern Egyptian Art in Cairo. 


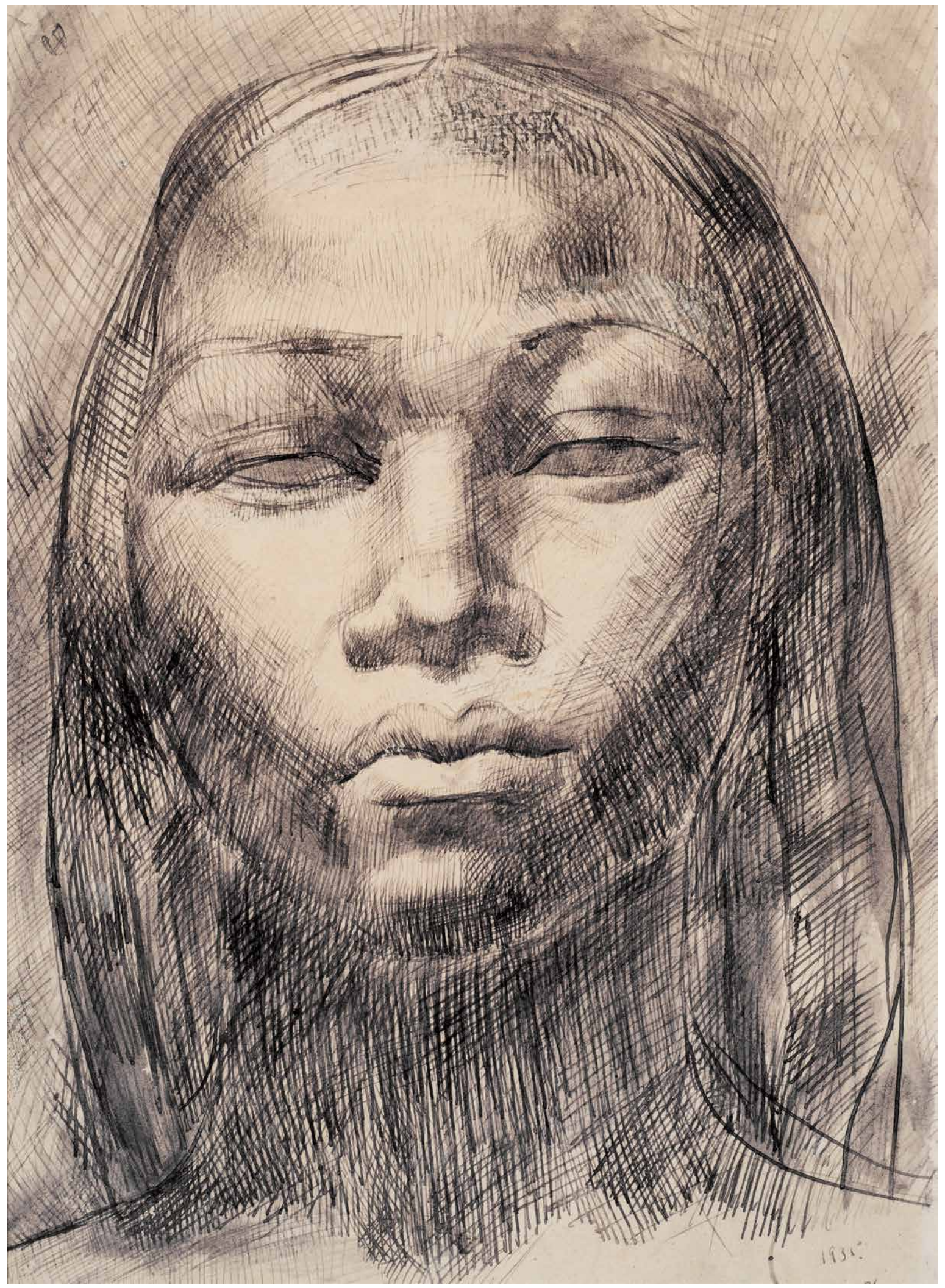

Amy Nimr Nubian Woman, Pencil and ink on paper, $25 \times 35 \mathrm{~cm}$. Courtesy of Museum of Modern Egyptian Art in Cairo. 


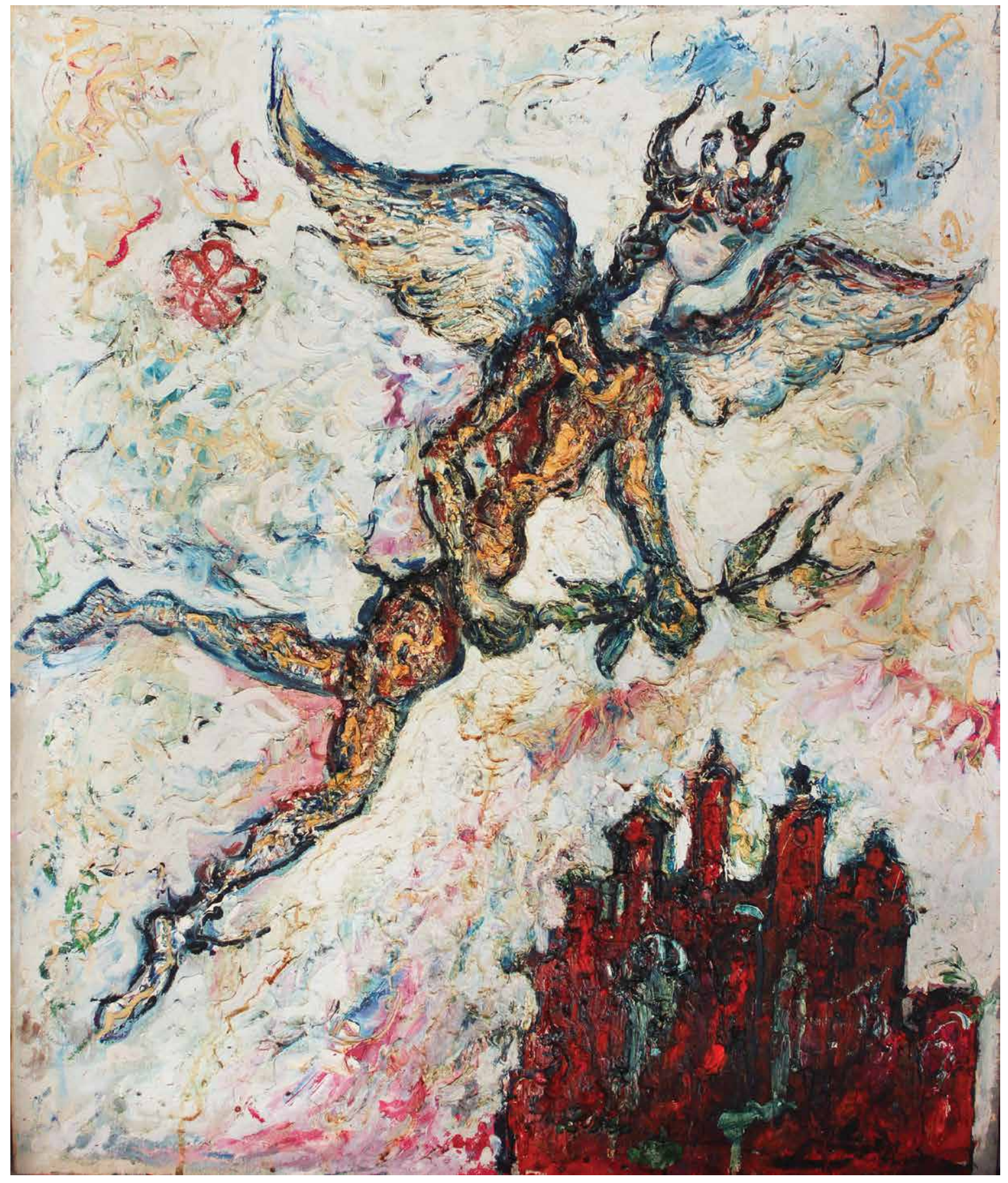

Ibrahim Massouda, Untitled, early 1950s, Oil on canvas, 82.5 x 72 cm, Sharjah Art Foundation Collection. 


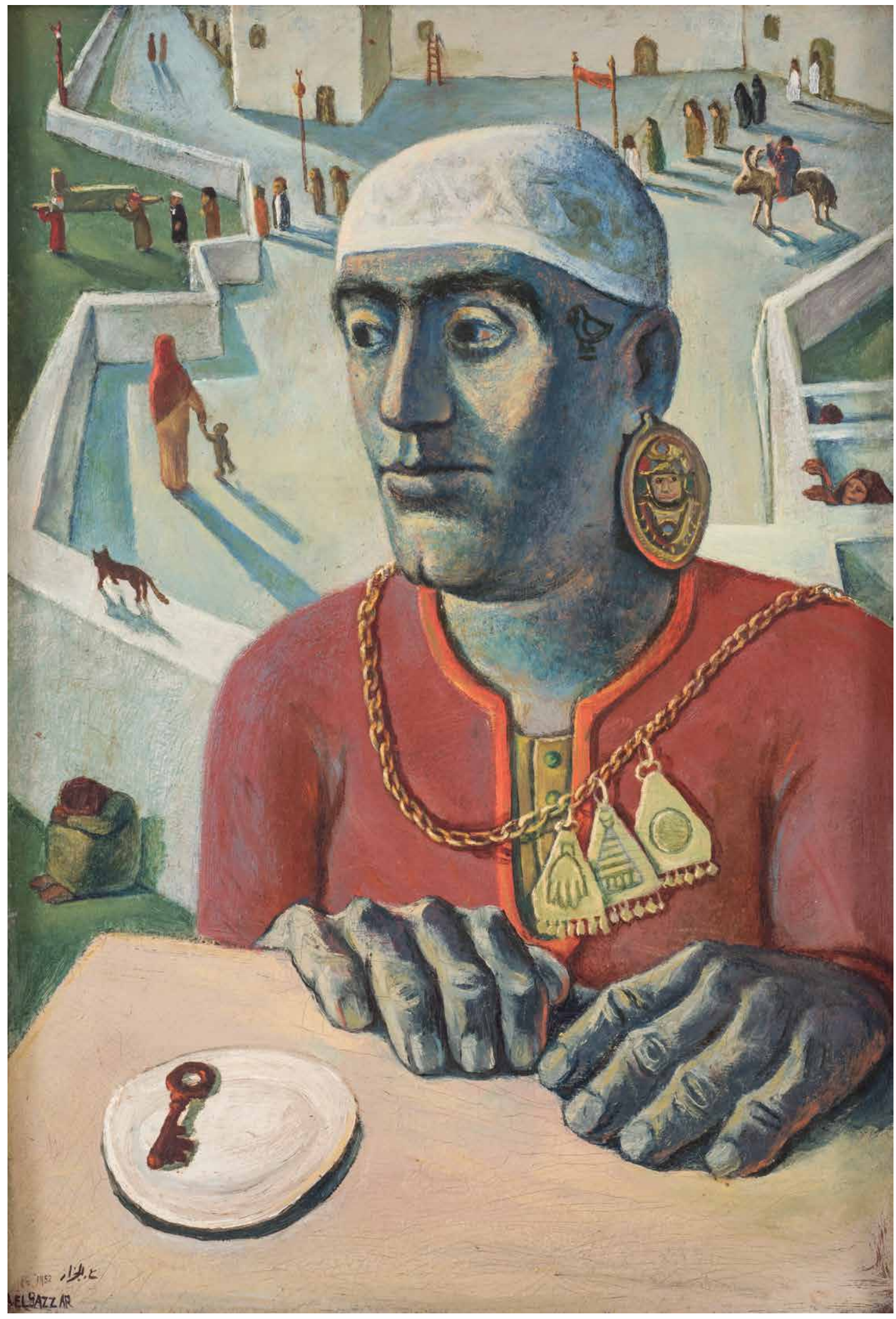

Abdel Hadi El-Gazzar, Key of Time, 1951, Oil on canvas, 89 x $60 \mathrm{~cm}$. Courtesy of Museum of Modern Arts Alexandria. 


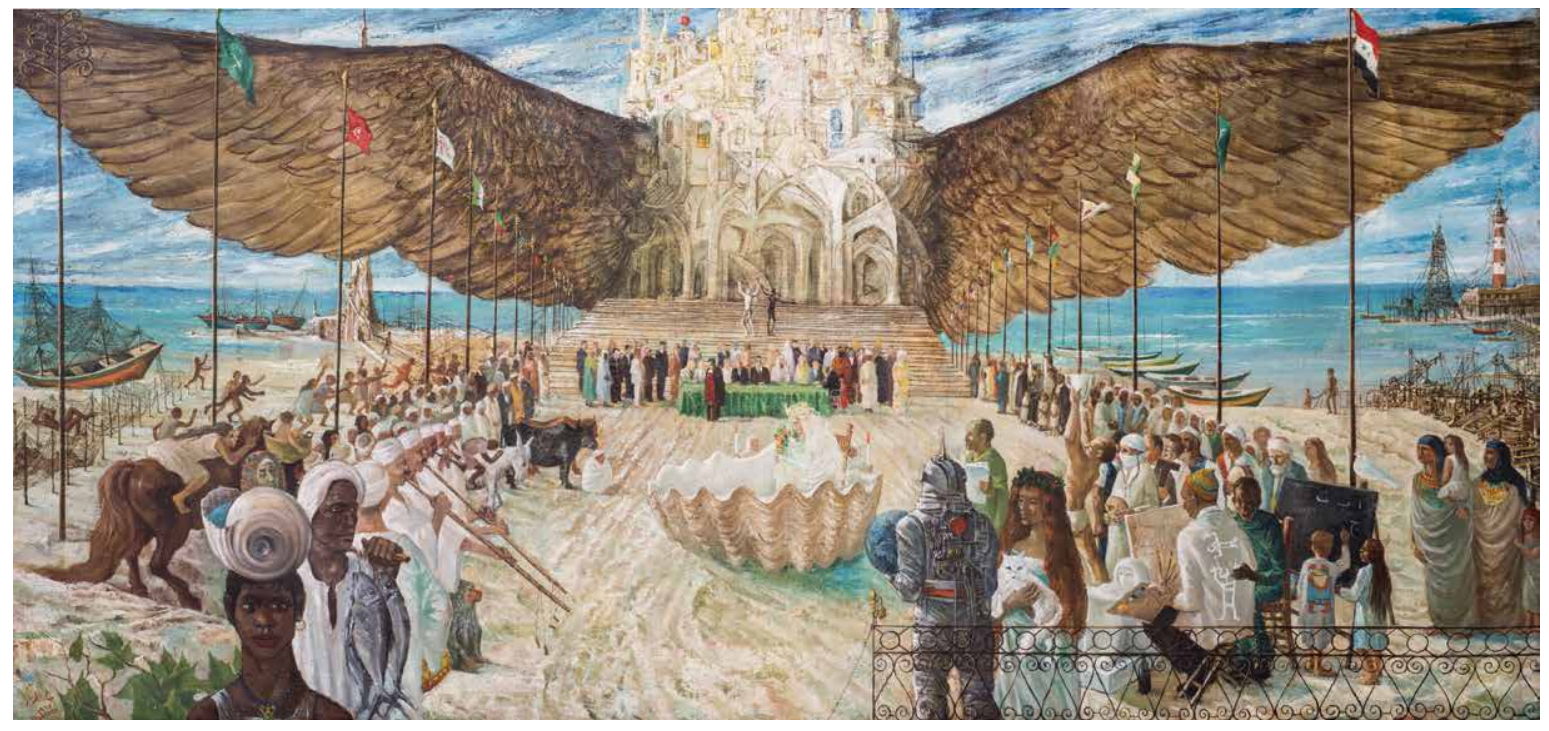

Abdel Hadi El-Gazzar, Peace, 1965, Oil on board, 80 x $170 \mathrm{~cm}$. Courtesy of Museum of Modern Egyptian Art in Cairo. 
